\title{
Artikel
}

\section{De stand van de stelselherziening: een nieuwe fase}

Mr. drs. C.D. (Lidia) Palm en mr. H.W. (Wilco) de Vos*

\section{Inleiding}

Een nieuwe lente, een nieuwe fase. $\mathrm{Na}$ een ogenschijnlijk rustige periode in de tweede helft van 2017 brengt 2018 veel nieuws voor de stelselherziening van het omgevingsrecht. De afgelopen maanden stonden in het teken van het uitbrengen en verwerken van de adviezen van de Afdeling advisering van de Raad van State (hierna: de Raad). Deze fase is op grond van de Wet op de Raad van State niet openbaar. Daardoor kan de indruk ontstaan dat er niet veel ontwikkelingen zijn. Er is echter, eerst bij de Raad en vervolgens bij de ministeries, veel werk verzet. Dat zal de komende maanden duidelijk worden.

De adviezen van de Raad hebben betrekking op de ontwerpen van de vier AMvB's op grond van de Omgevingswet, ${ }^{1}$ het voorstel voor de Invoeringswet Omgevingswet (hierna: Invoeringswet) en de voorstellen voor de Aanvullingswetten bodem, geluid en natuur. Samen een pakket aan regels dat een belangrijk vervolg geeft aan de stelselherziening van het omgevingsrecht. De adviezen zijn in etappes gevraagd en uitgebracht. De

Mr. drs. C.D. Palm is als MT-lid werkzaam bij de programmadirectie Eenvoudig Beter bij het ministerie van Binnenlandse Zaken en Koninkrijksrelaties. Mr. H.W. de Vos is werkzaam bij de directie Constitutionele Zaken en Wetgeving van het ministerie van Binnenlandse Zaken en Koninkrijksrelaties en als juridisch projectleider betrokken bij de totstandkoming van de nieuwe omgevingswetgeving. Het artikel is op persoonlijke titel geschreven. De tekst van dit artikel is afgesloten op 1 mei 2018.

1. Het Besluit kwaliteit leefomgeving (Bkl), het Besluit activiteiten leefomgeving (Bal), het Besluit bouwwerken leefomgeving (Bbl) en het Omgevingsbesluit $(\mathrm{Ob})$. adviezen over de voorstellen voor de Aanvullingswetten bodem en geluid dateren van 19 mei 2017, ${ }^{2}$ de adviezen over de ontwerp-AMvB's en het voorstel voor de Invoeringswet van 22 december 2017. ${ }^{3}$ Het laatste advies, over het voorstel voor de Aanvullingswet natuur, is uitgebracht op 8 maart 2018. ${ }^{4}$

Het nieuwe kabinet maakt werk van de stelselherziening. Het jaar begon met het uitbrengen van het nader rapport en het indienen bij de Tweede Kamer van het aanvullingswetsvoorstel bodem. ${ }^{5}$ Ondertussen wordt gewerkt aan de verwerking van de adviezen op de ontwerpen van de vier AMvB's en de voorstellen voor de Invoeringswet, de Aanvullingswet geluid en de Aanvullingswet natuur. Last but not least is in maart het voorstel voor de Aanvullingswet grondeigendom voor advies aan de Raad aangeboden. ${ }^{6}$

Zoals in een vorig nummer van dit tijdschrift aan de orde kwam, ${ }^{7}$ heeft de voortzetting van de stelselherziening een plek gekregen in het regeerakkoord van Rutte III. ${ }^{8}$ De verantwoordelijkheid voor de stelselherziening omgevingsrecht valt sinds de kabinetswisseling onder de minister van Binnenlandse Zaken en Koninkrijksrelaties (BZK) (Ollongren). Dat geldt ook voor de Nationale

Kamerstukken II 2017/18, 34 864, nr. 4

3. Zie www.raadvanstate.nl/adviezen/actuele-adviezen/vastgesteldeadviezen/vastgestelde-adviezen.html?id=871.

4. Zie www.raadvanstate.nl/adviezen/actuele-adviezen/vastgesteldeadviezen/vastgestelde-adviezen. html?id=881

5. Kamerstukken II 2017/18, 34 864, nrs. 1-2.

6. Zie www.raadvanstate.nl/adviezen/actuele-adviezen/aanhangigeadviezen.html.

7. H.A.J. Gierveld, De stand van zaken van de stelselherziening: een nieuw regeerakkoord, TO 2017, afl. 4, p. 156-160.

8. Vertrouwen in de toekomst. Regeerakkoord 2017-2021, VVD, CDA, D66 en ChristenUnie. Het regeerakkoord is te raadplegen via www. rijksoverheid.nl/regering. 
Omgevingsvisie en de ruimtelijke ordening. Evenals onder het vorige kabinet het geval was, strekt het nieuwe stelsel zich ook uit over onderwerpen die primair tot de verantwoordelijkheid van andere bewindspersonen behoren. Denk aan onderwerpen als infrastructuur, water, milieu, monumenten en mijnbouw. Dit blijkt bijvoorbeeld uit het feit dat de staatssecretaris van Infrastructuur en Waterstaat (IenW) primair verantwoordelijk is voor de Aanvullingswetten bodem en geluid en de minister van Landbouw, Natuur en Voedselkwaliteit (LNV) voor de Aanvullingswet natuur. Voor deze in voorbereiding zijnde wetten is de minister van BZK medeondertekenaar vanwege de verantwoordelijkheid voor het gehele stelsel. In welke commissie de Tweede Kamer de voorstellen zal behandelen, is nog even afwachten. Het voorstel voor de Aanvullingswet bodem wordt door de Vaste commissie voor Binnenlandse Zaken voorbereid. ${ }^{9}$ Hoe dan ook, de verwezenlijking van de stelselherziening is en blijft een zaak van het gehele kabinet en parlement. Over de stand van zaken, het voorgenomen proces en de planning van de verschillende onderdelen, op weg naar inwerkingtreding op 1 januari 2021, heeft minister Ollongren een brief aan het parlement gezonden. ${ }^{10}$ Daarin wordt ook ingegaan op onderwerpen als implementatie en de totstandkoming van het digitaal stelsel Omgevingswet (DSO).

In deze bijdrage laten wij enkele ontwikkelingen in de regelgeving de revue passeren. Daarbij zullen we onder meer ingaan op de algemene lijn die de Raad van State zal hanteren bij advisering over de wetgevingsproducten van de stelselherziening. Die is belangrijk voor de verdere vormgeving van het nieuwe stelsel.

\section{Algemene lijn voor advisering over wetgevings- producten van de stelselherziening}

In het advies over het voorstel voor de Aanvullingswet bodem beschrijft de Raad de algemene lijn aan de hand waarvan de Raad zal adviseren over toekomstige onderdelen van de stelselherziening van het omgevingsrecht. ${ }^{11}$ Deze lijn is voor de gehele stelselherziening van belang. De algemene lijn zal blijkens het advies bijvoorbeeld ook worden gehanteerd bij de advisering over het ontwerp van de op de Omgevingswet gebaseerde AMvB's en het voorstel voor de Invoeringswet. De Raad geeft hiermee een doorkijkje naar de toetsing van andere wetgevings-

9. Het wetsvoorstel was oorspronkelijk in handen gesteld van de Vaste commissie voor Infrastructuur en Waterstaat. Die commissie heeft de Vaste commissie voor Binnenlandse Zaken verzocht de behandeling van het wetsvoorstel over te nemen, hetgeen is gebeurd. Zie www. tweedekamer.nl/debat_en_vergadering/commissievergaderingen/ details?id=2017A04268

10. Kamerstukken II 2017/18, 33 118, nr. 102

11. Kamerstukken II 2017/18, 34 864, nr. 4. producten. De Raad geeft aan die wetgevingsproducten te zullen toetsen aan de verbeterdoelen en uitgangspunten van de stelselherziening (zoals een gelijkwaardig beschermingsniveau), de maatschappelijke doelen van de Omgevingswet en de belangrijkste systeemkeuzes. Ook geeft de Raad aan dat de nieuwe regelgeving zal worden onderzocht op consistentie met de kerninstrumenten. Deze algemene lijn voor de advisering door de Raad sluit daarmee nauw aan bij de bouwstenen van het nieuwe stelsel.

De Raad gaat in zijn advies specifiek in op de systeemkeuze in de Omgevingswet om de materiële normstelling grotendeels te bundelen in een beperkt aantal AMvB's. De Raad wijst op enkele wijzigingen, die mede naar aanleiding van het advies van de Raad in de Omgevingswet zijn aangebracht, waarmee de delegatiegrondslagen in de Omgevingswet nader met waarborgen zijn omkleed. De Raad geeft vervolgens expliciet aan dat hij de door de wetgever bij de Omgevingswet gemaakte keuzes voor het nieuwe stelsel, waaronder de keuze van de AMvB als basisniveau voor inhoudelijke normstelling, als uitgangspunt neemt voor de verdere advisering. Dit geldt dus ook voor de advisering over de AMvB's op grond van de Omgevingswet, de Invoeringswet en de Aanvullingswetten.

In het nader rapport geeft de regering aan dat zij de door de Raad geboden duidelijkheid waardeert. De algemene lijn voor advisering komt ten goede aan de consistentie van de verdere opbouw en inrichting van het nieuwe stelsel. ${ }^{12}$

\section{Advies over en vervolg van de Aanvullingswet bodem}

De Raad heeft over het voorgelegde voorstel voor de Aanvullingswet bodem een positief advies gegeven (dictum 3). Naast de hierboven beschreven algemene lijn voor de advisering bevat het enkele specifieke opmerkingen. De belangrijkste gaan over het gelijkwaardig beschermingsniveau en de toevalsvondst van verontreiniging op of in de bodem. De Raad maakt opmerkingen over het gelijkwaardig beschermingsniveau en geeft vanuit die invalshoek andachtspunten in relatie tot zorgplichten en het normenstelsel waarmee rekening gehouden kan worden in de uitvoeringsregelgeving. Deze aandachtspunten bieden duidelijkheid over de manier waarop de Raad die uitvoeringsregelgeving zal beoordelen. De aandachtspunten hebben niet tot aanpassing van het wetsvoorstel geleid, maar tot de toezegging van de regering dat in de nota van toelichting bij het voorgenomen Aanvullingsbesluit bodem aandacht zal worden besteed aan het gelijkwaardig beschermingsniveau. 
De Raad onderschrijft de wenselijkheid van de regeling voor een toevalsvondst van verontreiniging met onaanvaardbare risico's. Tegelijk maakt de Raad zich zorgen over de vraag of de veroorzaker daardoor buiten schot blijft en of het instrument adequaat is voor zorgwekkende verontreiniging in grondwater of risico's voor plant en dier. De Raad adviseert daarom de regeling voor de toevalsvondst uit te breiden.

In het nader rapport is aangegeven dat de Raad kennelijk een ander beeld heeft gekregen van het instrument van de toevalsvondst dan de regering heeft beoogd. De Raad heeft de toevalsvondst kennelijk opgevat als het equivalent van bodemsanering, hetgeen door de regering niet was beoogd. Het advies van de Raad heeft geleid tot een andere opzet van de passages in de toelichting over de toevalsvondst. Door het beschrijven van de verhouding tussen de toevalsvondst, de algemene zorgplicht in de Omgevingswet en het ongewone voorval (regels over onverwachte nadelige gevolgen tijdens activiteiten) wordt de afbakening met deze instrumenten scherper. Daarbij is een concretere invulling gegeven aan de verplichtingen die eenieder heeft om zorgvuldig om te gaan met de leefomgeving.

$\mathrm{Na}$ de verwerking van het advies is het voorstel ingediend bij de Tweede Kamer. De Vaste commissie voor Binnenlandse Zaken van de Tweede Kamer heeft op 16 maart 2018 het verslag ${ }^{13}$ uitgebracht over het aanvullingswetsvoorstel. Er zijn vragen gesteld door de leden van de fracties van de VVD, het CDA, D66 en GroenLinks. De regering is nu aan zet om de vragen te beantwoorden.

\section{Ontwikkelingen in \\ aanverwante wetgeving}

\subsection{Afschaffen actualiseringsplicht Wet ruimtelijke ordening}

Vooruitlopend op de inwerkingtreding van het nieuwe stelsel is een wetsvoorstel in procedure gebracht tot wijziging van de Wet ruimtelijke ordening (Wro) en de Invoeringswet Wet ruimtelijke ordening. ${ }^{14}$ Dit voorstel schaft, voor bestemmingsplannen en beheersverordeningen die digitaal raadpleegbaar zijn, de actualiseringsplicht af die op grond van de Wro geldt. Als niet aan de actualisatieverplichting is voldaan, geldt op grond van die wet een zogenoemde legessanctie. Dit betekent dat er geen leges kunnen worden geheven die verband houden met het bestemmingsplan of de beheersverordening. ${ }^{15}$ Een groot antal gemeenten zou hierdoor voor de datum van inwerkingtreding van de Omgevingswet hun bestaande bestemmingsplan of beheersverordening moeten actualiseren. Door het ingediende wetsvoorstel kunnen gemeenten ervoor kiezen om dat niet nu te

13. Kamerstukken II 2017/18, 34 864, nr. 5.

14. Kamerstukken II 2016/17, 34 666, nr. 2.

15. Art. 3.1 lid 4 Wro. doen, maar die capaciteit te gebruiken voor de voorbereiding van omgevingsplannen.

Voor dit voorstel is eind vorig jaar de nota naar aanleiding van het verslag uitgebracht. Het voorstel is vervolgens op 1 februari 2018 als hamerstuk aangenomen door de Tweede Kamer. Ook in de Eerste Kamer heeft behandeling inmiddels plaatsgevonden. Op 17 april 2018 is het wetsvoorstel als hamerstuk aangenomen. $\mathrm{Na}$ bekrachtiging door de Koning zal de wet in het Staatsblad worden gepubliceerd. Omdat de Wet raadgevend referendum op het wetsvoorstel van toepassing is, kan de wet niet eerder dan acht weken na de bekrachtiging in werking treden.

\subsection{Wijziging van de Awb in verband met het nieuwe omgevingsrecht}

De Algemene wet bestuursrecht (Awb) moet op onderdelen worden aangepast om aan te sluiten op het nieuwe omgevingsrecht. Deze wijzigingen zijn nodig om het stelsel van de Omgevingswet in werking te kunnen laten treden. Begin van dit jaar is de internetconsultatie voor het voorstel voor wijziging van de Awb van start gegaan. ${ }^{16}$ De reactieperiode loopt tot en met 18 mei 2018.

Het wetsvoorstel bevat een wijziging van de coördinatieregeling van afdeling 3.5 Awb. Hierbij gaat het om samenhangende besluiten van bestuursorganen op aanvragen voor vergunningen en ontheffingen door burgers en bedrijven. De nieuw voorgestelde regeling vervangt de bestaande coördinatieregelingen uit de Awb en enkele wetten op het terrein van het omgevingsrecht. Deze worden nu verdergaand geharmoniseerd. De nieuwe coördinatieregeling is zo opgesteld dat geen aparte coördinatieregeling voor het omgevingsrecht meer nodig is.

De voorgestelde regeling bevat enkele vernieuwingen, die zijn ontleend aan verschillende coördinatieregelingen uit bijzondere wetten. Een belangrijke vernieuwing is art. 3:27, dat regelt dat in bepaalde gevallen de bevoegde minister of gedeputeerde staten de besluitvorming kunnen overnemen (indeplaatstredingsbevoegdheid) als het eigenlijk bevoegde bestuursorgaan niet of niet tijdig een besluit neemt of een besluit neemt dat de goede uitvoering van een daaraan ten grondslag liggend besluit in de wielen rijdt. Een dergelijke voorziening staat op dit moment al in de Wro en de Tracéwet en wordt hiermee dus onderdeel van de coördinatieregeling van de Awb.

Daarnaast wordt in hoofdstuk 5 Awb (handhaving) de mogelijkheid opgenomen om overtreding van de medewerkingsplicht bestuurlijk te handhaven. Art. 5:20 Awb verplicht eenieder om aan een toezichthouder de nodige medewerking te verlenen bij de uitoefening van diens bevoegdheden. Op schending van deze verplichting stelt de Awb geen bestuursrechtelijke sanctie. Het werd voldoende geacht dat de sanctionering verliep via de mogelijkheid van strafvervolging op basis van art. 184 van het Wetboek van Strafrecht (strafbaarstelling overtreding

16. Zie https://www.internetconsultatie.nl/awbomgevingswet. 
ambtelijk bevel). Tegenwoordig biedt een groot aantal sectorale wetten, waaronder ook de Wet algemene bepalingen omgevingsrecht (Wabo), de mogelijkheid om bij overtreding van art. 5:20 Awb bestuursdwang toe te passen. Met het nieuw voorgestelde derde lid van art. 5:20 wordt deze bevoegdheid overgeplant naar de Awb, zodat voortaan elk bestuursorgaan over deze mogelijkheid beschikt. Gelet op de ontwikkelingen in de bestuurlijke handhaving is dit een logische stap.

Tot slot worden enkele bijzondere nadeelcompensatieregelingen ingetrokken of aangepast met het oog op de inwerkingtreding van de algemene nadeelcompensatieregeling van titel 4.5 Awb (nadeelcompensatie).

\section{Komende ontwikkelingen}

\subsection{AMvB's, Invoeringswet en}

Aanvullingswetten geluid en natuur

Zoals hierboven is vermeld, heeft de Raad advies uitgebracht over de ontwerp-AMvB's en het voorstel voor de Invoeringswet. Deze ontwerpregelgeving is, ter uitvoering van eerdere toezeggingen, tegelijk voor advies voorgelegd, zodat de Raad deze in samenhang kan beoordelen. $\mathrm{Nu}$ de Raad advies heeft uitgebracht, is de volgende stap dat in reactie daarop het nader rapport wordt vastgesteld en de adviezen worden verwerkt. De AMvB's zullen na verwerking van het advies worden vastgesteld en in het Staatsblad worden gepubliceerd. Dan worden ook het advies en het nader rapport openbaar en zal de minister van BZK de Eerste en Tweede Kamer daarvan op de hoogte stellen. Voor het voorstel voor de Invoeringswet is de volgende stap dat het zal worden ingediend bij de Tweede Kamer, waarna de parlementaire behandeling van start gaat. Dat geldt ook voor de voorstellen voor de Aanvullingswet geluid en de Aanvullingswet natuur.

\subsection{Aanvullingswet grondeigendom}

Op 20 januari 2017 heeft de minister van IenM een brief aan de Tweede Kamer gezonden over het onderwerp onteigening. ${ }^{17}$ Daarin wordt aangekondigd dat de wettelijke regeling zo zal worden ingericht dat bij de besluitvorming over onteigening altijd de bestuursrechter wordt betrokken. Dit naar aanleiding van de consultatie en de ingewonnen adviezen van de Aanvullingswet grondeigendom. Hiermee wordt tegemoetgekomen aan de bezwaren van partijen die vreesden voor vermindering van de positie en rechtsbescherming van een eigenaar. Met de voorgestelde aanpassing wordt gewaarborgd dat het uitgesloten is dat een eigenaar wordt onteigend zonder dat de bestuursrechter zich over de onteigening heeft uitgesproken.

In de afgelopen periode is, na raadpleging van de meest betrokken partijen, waaronder de Raad voor de recht- spraak $^{18}$ en de Afdeling bestuursrecht van de Raad van State, de regeling verder uitgewerkt. De primaire verantwoordelijkheid voor het wetsvoorstel berust sinds de kabinetswisseling bij de minister van BZK. Het wetsvoorstel is in maart van dit jaar voorgelegd aan de Afdeling advisering van de Raad van State.

\section{Slot}

2018 wordt een belangrijk jaar voor de stelselherziening. Duidelijk is dat het nieuwe kabinet werk maakt van de uitvoering van het regeerakkoord. Voor een groot aantal producten van de stelselherziening wordt een belangrijke volgende stap gezet. Zo komen steeds meer stukjes van de puzzel van het nieuwe stelsel op hun plek te liggen en kunnen partijen in de praktijk zich beter en gerichter voorbereiden op de inwerkingtreding van het stelsel op 1 januari 2021. In een volgende aflevering van dit tijdschrift zullen de adviezen van de Raad over de AMvB's en de Invoeringswet en de reactie van de regering bekend zijn en inhoudelijk worden besproken. Die leggen op hun beurt weer de basis voor de uitwerking via het Invoeringsbesluit en de Aanvullingsbesluiten. Verder zal de komende tijd het voorstel voor de Aanvullingswet bodem door de Tweede Kamer worden behandeld. Dit is het eerste voorstel van het nieuwe kabinet dat door de Kamer in de huidige samenstelling zal worden behandeld. Kortom, het belooft voor de stelselherziening een boeiend jaar te worden. 